\title{
Positron study of adsorption of $n$-heptane in SBA-3
}

\author{
Radosław Zaleski $^{1}$ [D $\cdot$ Marek Gorgol $^{1} \cdot$ Jacek Goworek $^{2} \cdot$ Agnieszka Kierys $^{2} \cdot$ Marek Pietrow $^{1} \cdot$ Bożena Zgardzińska $^{1}$
}

Received: 30 November 2018 / Revised: 12 March 2019 / Accepted: 10 April 2019 / Published online: 6 May 2019

(c) The Author(s) 2019

\begin{abstract}
The sorption of n-heptane in the SBA-3 silica was investigated using positron annihilation lifetime spectroscopy (PALS). The PALS technique allows to study in situ evolution of pore filling by the n-alkane. In the dry SBA-3, the free volumes attributed to the silica skeleton, micropores, mesopores as well as intergranular spaces can be distinguished by PALS as various ortho-positronium components. The liquid n-heptane appears as an additional component, which allows to monitor adsorption and desorption using the ortho-positronium parameters. Filling the SBA-3 silica with n-heptane leads to the rapid, already at $\mathrm{p} / \mathrm{p}_{0}=0.08$, disappearance of the pore-related components. Simultaneously, a large increase in the intensity of the components attributed to liquid n-heptane is observed. The adsorption proceeds slightly faster than the desorption, which is most likely the consequence of the difference in the alkane-alkane and alkane-silica interaction forces. The pore size distributions calculated for $\mathrm{n}$-heptane and water from the PALS results clearly indicate that the mechanism of sorption is different for both liquids. This can result from the different strength of the interactions between molecules of each liquid and between the liquid and the atoms of pore walls.
\end{abstract}

Keywords n-Heptane adsorption $\cdot$ SBA-3 ordered mesoporous material $\cdot$ Positron annihilation $\cdot$ Pore size distribution

\section{Introduction}

The course of many physical, biological and geological processes is very often related to liquids confined in nanodomains (Wheeler and Stroock 2008). The confined liquids also plays a significant role in multiple fields of science and industry, e.g. catalysis, nanofiltration and separation of chemicals (Kolomeisky and Kotsev 2008; Sparreboom et al. 2009; Agah et al. 2015). It is well known that the properties of liquids in a spatially restricted region are significantly different from the bulk phase. Both the spatial confinement and interactions with the surface of nanodomains underlie these differences (Crupi et al. 2002; Całus et al.

This article belongs to S.I. ISSHAC10, but it reach the press at the time the special issue was published.

Radosław Zaleski

radek@zaleski.umcs.pl

1 Department of Nuclear Methods, Institute of Physics, Maria Curie-Sklodowska University, pl. M. Curie-Sklodowskiej 1, 20-031 Lublin, Poland

2 Department of Adsorption, Faculty of Chemistry, Maria Curie-Sklodowska University, Pl. M. Curie-Sklodowskiej 3, 20-031 Lublin, Poland
2015). A comprehensive understanding of the fundamentals of the confined liquids behaviour is crucial for the design and practical use of porous materials. This, in turn, can be achieved by getting to know the mechanism of adsorption and transport through nanochannels. Various theoretical and experimental approaches have been developed to study the aforementioned processes in materials of different type (Babarao and Jiang 2010). They reveal that beside the pore geometry and composition of channel walls, also temperature and the properties of the adsorbate strongly affect the processes of adsorption and desorption as well as their kinetics (Docampo-Álvarez et al. 2016; Jiang et al. 2007; Saihara et al. 2015).

A nonstandard approach to study adsorption by observation in situ of the size and concentration of the liquidfree cavities is provided by positron annihilation lifetime spectroscopy (PALS) (Maheshwari et al. 2017; Kierys et al. 2013a; Ito et al. 2018). A nanoscale probes, positron ( $\mathrm{e}^{+}$, the antiparticle of electron), and positronium (Ps, the unstable hydrogen-like atom of electron and positron) used in the PALS technique are very sensitive to the electron density and chemical composition of matter (molecular environment of Ps). The lifetime and intensity of the triplet state of Ps, ortho-positronium (o-Ps), are widely used to determine the 
structure of matter: the size and concentration of free volumes in media (Hautojärvi 1979).

It has been previously shown that o-Ps can be successfully used to study various porous silicas. The pore sizes can be determined on the basis of the average o-Ps lifetimes and the relative intensities correlate with the pore concentration (Zaleski 2015). Unfortunately, the straightforward interpretation leads to incorrect conclusions for some materials (Kierys et al. 2013a). This is caused by the o-Ps migration between free volumes of different size if they are connected (Zaleski et al. 2013). This effect has to be taken into account to obtain reliable results. On the other hand, o-Ps creates a sub-nanometer bubble when it is formed in fluids. The balance between the external pressure, o-Ps zero-point motion and surface tension determines the size of the bubble (Ferrell 1957). Thus, although PALS is a powerful tool for monitoring adsorption, the variety of processes accompanying the o-Ps interaction with matter makes the interpretation of the PALS results a complex issue.

$\mathrm{N}$-heptane was selected as the adsorbate in this study since it is an important member of volatile organic compounds-VOCs, whose recovery and reuse from polluted air streams are crucial from the economic and environmental point of view (Liu et al. 2006; Dabelstein et al. 2000). The search for an effective and efficient technology of VOC separation and recovery also involves study of their adsorption on various materials and it is still under investigation (Lin et al. 2012; Zhang et al. 2016, 2017).

The SBA-3 silica (Chen et al. 2004) provides nearly a model system with cylindrical pores of the uniform diameter of $2 \mathrm{~nm}$ (Maheshwari et al. 2017). Among various porous materials, SBA-3 emerges as a very interesting material to investigate adsorption and desorption of $n$-heptane. For example, this system of uniform pores may be compared and treated as vascular tissue in the transport system of plants.

Unlike polymeric materials, which swell upon their exposure to various solvents in the liquid or vapour phase (Zaleski et al. 2017), the system of SBA-3 pores is rigid. Hence, the use of SBA-3 for the adsorption-desorption study of the selected adsorbent allows neglecting the effects associated with its swelling. Only the processes of the adsorbate transportation in pore system, which are related to the pore geometry, chemical composition of pore walls and thereby the interaction between the molecules of adsorbate and adsorbate and surface of pore walls, are to be considered during adsorption-desorption experiments.

An important advantage of the SBA-3 in the PALS studies is negligibly small migration of positronium outside the primary pores (Zaleski et al. 2013). An entirely different situation occurred in the case of SBA-15, where the positronium migration dominates over annihilation, which in turn caused difficulties with the interpretation of the adsorption-desorption results (Kierys et al. 2013a).
Hence, SBA-3 was selected as the adsorbent for the examination of $n$-heptane adsorption-desorption by PALS. Moreover, from information provided by PALS about the amount of adsorbed n-heptane, the pore size distributions of SBA-3 were calculated. For comparative purposes, pore size distributions from water adsorption and desorption on SBA-3 were also calculated. Comparing PSDs derived from adsorption data of different adsorbates provides results which makes it possible to indicate the differences between adsorption mechanism of both liquids. Their understanding has great cognitive and utilitarian importance.

\section{Experimental}

SBA-3 was synthesized following a procedure described in the literature (Chen et al. 2004) using dodecyltrimethylammonium bromide (C12TAB, Aldrich) as structure directing agent (surfactant) and tetraethoxysilane (TEOS, Aldrich, 98\%) as silica source, Aldrich). The starting molar composition of the reacting mixture was TEOS (1): CTAB (9): $\mathrm{HCl}(0,137): \mathrm{H}_{2} \mathrm{O}$ (130). The as-synthesized silicasurfactant mesophase was filtered, washed with distilled water, dried in air at $373 \mathrm{~K}$ and finally calcined by heating up $(1 \% \mathrm{~min})$ to $823 \mathrm{~K}$ in air for $5 \mathrm{~h}$. The parameters characterizing the SBA-3 silica porosity determined by nitrogen adsorption-desorption at $77 \mathrm{~K}$ are as follows: the specific surface area $\left(S_{\mathrm{BET}}\right.$, (Brunauer et al. 1938) $)-1030 \mathrm{~m}^{2} / \mathrm{g}$, the total pore volume $-0.506 \mathrm{~cm}^{3} / \mathrm{g}$, the pore-size distribution derived from the adsorption branch of isotherm using the NLDFT method-primary pores with the diameter of ca. $2 \mathrm{~nm}$. The detailed description of their measurement is given in (Maheshwari et al. 2017). The length of majority of the pores is of order of several micrometers as estimated from SEM micrographs.

The SBA-3 sample with the ${ }^{22} \mathrm{Na}$ radioactive positron source (activity of $200 \mathrm{kBq}$ enclosed in $8 \mu \mathrm{m}$ Kapton foil) in the middle was placed inside a vacuum chamber equipped with the gas applying system. The sample was initially degassed and cleaned of impurities by keeping for $12 \mathrm{~h}$ at $473 \mathrm{~K}$ in high vacuum $\left(\mathrm{p}<10^{-4} \mathrm{~Pa}\right)$ obtained with the use of turbomolecular pump. A liquid n-heptane $(\mathrm{POCH}$, Poland, purity $>99 \%$, melting temperature of $183 \mathrm{~K}$ ) was placed inside a glass tube attached to the chamber and degassed with use of following procedure: the alkane was gradually frozen in liquid nitrogen, assuring the movement of impurities and dissolved air into space above the adsorbate, from where they were pumped out with the use of rotary pump in the next step; then, n-heptane was melted at room temperature. The procedure was repeated three times, each taking ca. $10 \mathrm{~min}$.

The adsorption was carried out by introducing the n-heptane vapours over the sample at given pressure through 
the gas dosing valve with a controlled leak. This step was repeated for over twenty pressures changed stepwise, $8 \mathrm{~h}$ per step. The temperature of the sample was stabilized assuring a constant value of $n$-heptane saturated vapour pressure.

The gamma quanta accompanying positron creation inside the source and the quanta from positron/positronium annihilation inside the sample were collected with the use of two $\mathrm{BaF}_{2}$ scintillation detectors. A standard fastslow delayed coincidence spectrometer was used to obtain PALS spectra. The resolution curve of the spectrometer was approximated by two Gaussians with the average FWHM values of $290 \mathrm{ps}$ and $500 \mathrm{ps}$ and the average intensity ratio of $80 / 20$, which were estimated from all fits of the analysed spectra. The spectra were analysed with the use of LT 9.2 program (Kansy 1996). A total count number was about 15 million per spectrum. Such high statistics was necessary to distinguish the components of low intensity.

\section{Results and discussion}

Several groups of free volumes characterized by a specific size are present in the studied SBA-3-n-heptane system. Each of them gives a contribution to the positron annihilation lifetime spectra as a separate o-Ps component $\left(\mathrm{C}_{\mathrm{n}}\right.$, where $n$ enumerates them). The components are characterized by lifetimes $\left(\tau_{n}\right)$, which are proportional to the size of the free volumes, and intensities $\left(\mathrm{I}_{\mathrm{n}}\right)$, which are proportional to the concentration of the free volumes. An exception are two short-lived components $\left(\mathrm{C}_{1}\right.$ and $\left.\mathrm{C}_{2}\right)$, which are attributed to para-positronium and unbound positrons annihilation and should not be connected to any specific fraction of free volumes in this case.

In dry SBA-3 dominates $\mathrm{C}_{5}$ with $\mathrm{I}_{5}=22 \%$, which originates from the primary mesopores of SBA-3 (Fig. 1). Apart from this, there are three components with intensity ca. 3\% each, which can be attributed to the silica skeleton $\left(\mathrm{C}_{3}\right)$, micropores $\left(\mathrm{C}_{4}\right)$ and intergranular spaces $\left(\mathrm{C}_{6}\right)$. Only two of o-Ps components remain after $\mathrm{n}$-heptane adsorption, but their major origin becomes different, i.e. the silica-liquid interface $\left(C_{3}\right)$ and the bubbles formed by o-Ps (Ferrell 1957) in liquid n-heptane, which occupy pores of SBA-3 $\left(\mathrm{C}_{4}\right)$. Simultaneously, there can be a significant contribution of the silica skeleton to $\mathrm{C}_{3}$. The transformation from the components characteristic for dry SBA-3 to the ones connected to liquid $n$-heptane can be observed on the basis of the change of their parameters $\left(\tau_{n}\right.$ and $\left.I_{n}\right)$. In turn, the course of this transformation allows to draw conclusions about the course and mechanisms of adsorption and desorption.

Unlike in SBA-15 (Kierys et al. 2013a), where virtually all o-Ps migrates from the primary mesopores to the intergranular spaces before annihilation, in SBA-3 changes in the filling of primary mesopores can be directly monitored by PALS. The most informative parameters are $\mathrm{I}_{4}$ and $\mathrm{I}_{5}$, which are proportional to the volume of liquid n-heptane and the remaining free volume of mesopores, respectively. Their pressure dependencies are almost a mutual reflection, i.e. $\Delta \mathrm{I}_{4} \approx-\Delta \mathrm{I}_{5}$, which indicates that $\mathrm{n}$-heptane is adsorbed mainly in mesopores.

During adsorption both $\mathrm{I}_{4}$ and $\mathrm{I}_{5}$ begin to change already at $\mathrm{p} / \mathrm{p}_{0}=0.02$ and retain the linear trend until $\mathrm{p} / \mathrm{p}_{0}$ reaches 0.08 . These values are clearly smaller than 0.12 and 0.16
Fig. 1 Lifetimes and intensities of ortho-positronium components as a function of the relative n-heptane pressure during adsorption and desorption. Uncertainties, if not shown, do not exceed symbol size
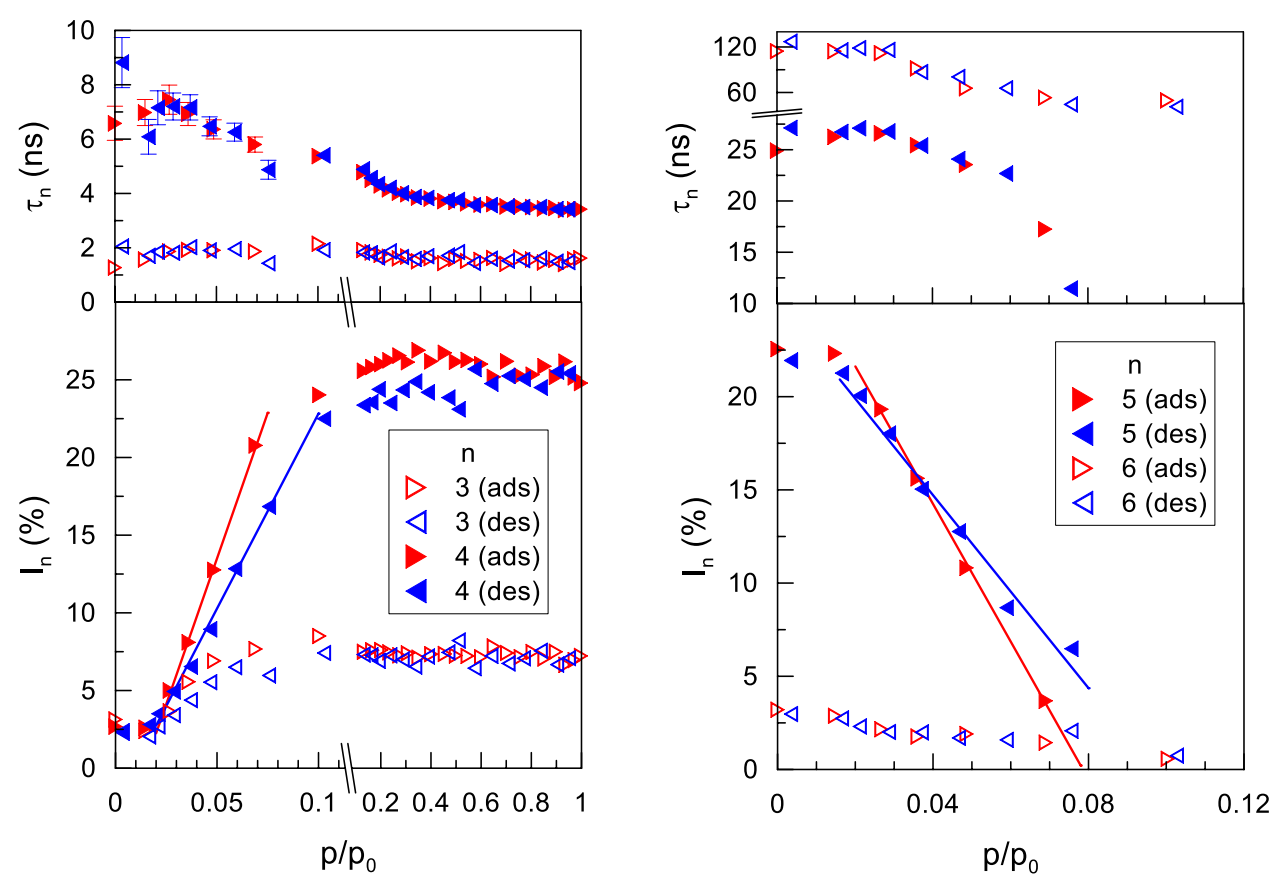
observed in classic adsorption experiment for similar MCM41 (Zandavi and Ward 2013). However, this is expected for pores of SBA-3 smaller by ca. $0.6 \mathrm{~nm}$ than those in MCM41 . These pressure values are significantly smaller than the analogous ones observed for water (Maheshwari et al. 2017) mostly due to much greater molar volume of n-heptane.

Above $\mathrm{p} / \mathrm{p}_{0}=0.08 \mathrm{C}_{5}$ disappears completely due to complete filling of mesopores by liquid n-heptane. In turn, $\mathrm{I}_{4}$ becomes stable indicating that no significant amount of liquid condensates outside primary mesopores. During desorption the changes of $I_{4}$ and $I_{5}$ are very similar, but the pressure dependence of both intensities has a slightly smaller slope. This suggests that during desorption an arrangement of $\mathrm{n}$-heptane molecules is slightly different than during adsorption, which, e.g., makes evaporation easier than condensation. Nevertheless, both adsorption and desorption occur within less than 0.08 of saturated vapour pressure confirming a great uniformity of the pores of SBA-3.

Unlike the intensities, the lifetimes of $\mathrm{C}_{4}$ and $\mathrm{C}_{5}$ vary in the same way during adsorption as during desorption. The increase in $\tau_{4}$ at low pressure is related to the negative pressure in the liquid under the concave menisci in accordance with the Young-Laplace law, which is common for confined n-heptane (Kierys et al. 2013a, b; Zaleski et al. 2012). The large spread of $\tau_{4}$ at pressure close to zero is due to the high sensitivity of $\mathrm{C}_{4}$ to statistical fluctuations of other (both shorter- and longer-lived) components. The reason for this is its low intensity $\left(\mathrm{I}_{4}\right)$.

The pressure dependence of $\tau_{5}$ is much more useful for deducing the course of adsorption and desorption, because it provides information about the evolution of the average size of this part of mesopores that remains free of $n$-heptane. There is only small change of $\tau_{5}$ below $\mathrm{p} / \mathrm{p}_{0}=0.06$, i.e. for over half of the mesopores filling/emptying range. This indicates that the diameter of the empty mesopores is very slightly reduced in relation to the initial one in comparison to the pore size reduction expected in the case of the formation of liquid monolayer. Thus, the liquid has to fill whole clearance of the pore in the form of plugs in the similar way as in the case of water (Maheshwari et al. 2017). Most likely the narrowest sections of pores are filled first and then n-heptane condensates in larger and larger parts of pores during adsorption. The course of desorption is opposite. Probably the slight decrease of $\tau_{5}$ above $\mathrm{p} / \mathrm{p}_{0}=0.04$ is related to the closing ends of the liquid plugs and shortening of the free space cylinders. This effect becomes very clear if $I_{5}$ is below $7 \%$, i.e. ca. $2 / 3$ part of pore volume (as estimated from $\mathrm{I}_{5}$ ) is filled by liquid.

The explanation presented above is consistent with the evolution of $\mathrm{C}_{3}$ with pressure. Lack of clear changes in $\tau_{3}$ allows to presume that this components originates from the free spaces between silica atoms in whole pressure range. Thus, the change in $I_{3}$ is the result of capping these free spaces that are at the surface of pores. Hypothetically, if there would be a layer of $n$-heptane on the pore surface at low pressure, $\mathrm{I}_{3}$ would increase, but $\mathrm{I}_{4}$ would remain small because pore walls are "capped", but there is not enough liquid volume to host the o-Ps bubble. This is not observed around $\mathrm{p} / \mathrm{p}_{0}=0.02$, however, $\mathrm{I}_{3}$ reaches saturation already at $\mathrm{p} / \mathrm{p}_{0}=0.06$, i.e. when $\tau_{5}$ is reduced. Therefore, the size reduction of nearly filled pores can be a consequence of decrease of their diameter due to appearance of the layer of $\mathrm{n}$-heptane covering the walls. In this case, the distribution of pore radii in SBA-3 would cross the threshold between cluster-like adsorption and layered adsorption.

According to the nitrogen adsorption method the volume of the intergranular spaces in SBA-3 that is detectable by PALS (i.e. below ca. $50 \mathrm{~nm}$ ) is negligible small in comparison to the volume of primary mesopores (Maheshwari et al. 2017). Despite this, $I_{6}$ is large enough to easily find this component. This is a result of the o-Ps migration phenomenon consisting in the escape of the some fraction of o-Ps, which is formed inside the primary mesopores, outside of them to the intergranular spaces. In consequence, the changes in $\mathrm{I}_{6}$ strongly depend on the connection between these two groups of pores. A condensation of $n$-heptane at the entrances of primary pores closes them for the escaping o-Ps and as a result $\mathrm{I}_{6}$ decreases. If primary mesopores are completely closed, $\mathrm{I}_{6}$ is below $0.2 \%$ and thus it can be neglected.

Also the change in $\tau_{6}$ is caused by closing the entrances of primary mesopores. The open entrances act like holes in the "walls" of intergranular spaces making them openwork-like. Such structure has relatively low electron density, which results in the large o-Ps lifetime (ca. $120 \mathrm{~ns}$ ). With filling the entrances with $n$-heptane, the holes disappear and the electron density increases. In consequence $\tau_{6}$ decreases without the significant decrease in the size of intergranular spaces. When all entrances are filled with liquid, $\tau_{6}$ is as low as $60 \mathrm{~ns}$. Due to very small $\mathrm{I}_{6}$ and a great uncertainty in $\tau_{6}$ it is impossible to judge whether intergranular spaces are filled at least partially by $\mathrm{n}$-heptane at high pressure (i.e. $\mathrm{p} / \mathrm{p}_{0}$ close to 1). Also $I_{4}$, which is related to the total volume of the liquid, do not show any detectable increase at high pressure. Thus, the amount of $\mathrm{n}$-heptane condensed in intergranular spaces is negligible in comparison to the one condensed in the primary mesopores.

Information about the amount of adsorbed liquid (like $\mathrm{n}$-heptane or water) provided by $\mathrm{I}_{4}$ is analogous to the adsorption isotherm obtained from classic volumetric adsorption systems. Thus, it can be used to calculate pore size distributions (PSDs), where the pore diameter is obtained from the Kelvin equation (Thomson 1871) and the pore volume is assumed to be proportional to $\mathrm{I}_{4}$. To obtain $\mathrm{dI}_{4} / \mathrm{dD}$ the gradient of $\mathrm{I}_{4}(\mathrm{D})$ is calculated. Applying this simple procedure allows to obtain nice bell-shaped PSDs from both adsorption and desorption of n-heptane (Fig. 2). The 


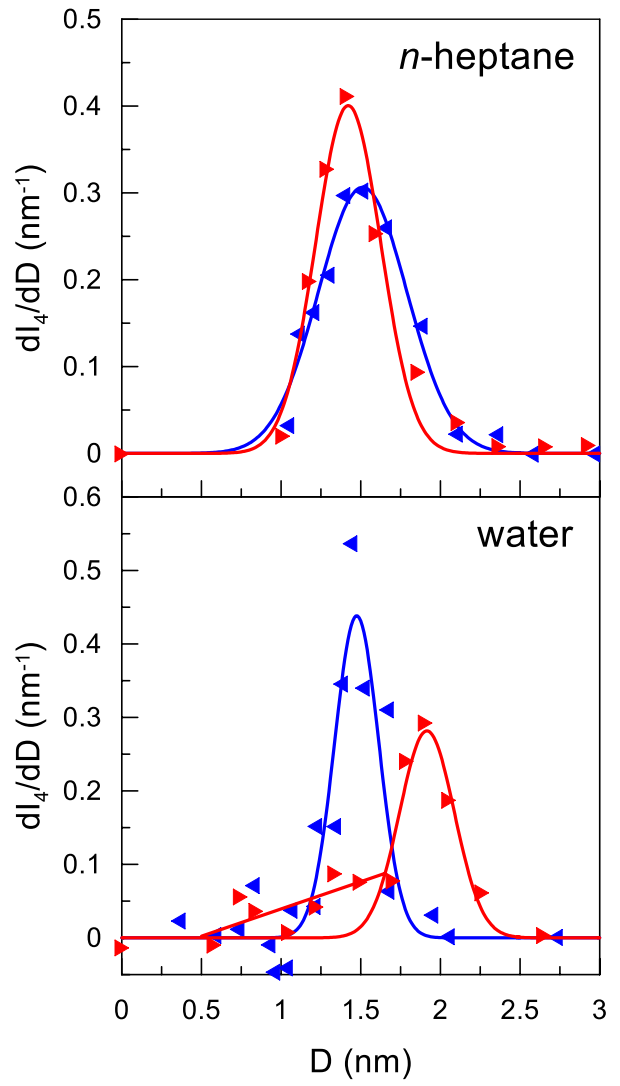

Fig. 2 Pore size distributions calculated on the rate of changes in $\mathrm{I}_{4}$ and the Kelvin equation. Right-pointing red triangles represent adsorption, while the left-pointing blue ones - desorption (Color figure online)

Table 1 The average pore diameters and width of the distribution obtained by fitting Gaussian functions to the PSDs calculated from the pressure dependences of $\mathrm{I}_{4}$

\begin{tabular}{llllll}
\hline & \multicolumn{2}{c}{$\mathrm{D}_{\text {avg }}(\mathrm{nm})$} & & & \multicolumn{2}{c}{$\sigma_{\mathrm{D}}(\mathrm{nm})$} & \\
\cline { 2 - 3 } & $\mathrm{n}$-Heptane & Water & & $\mathrm{n}$-Heptane & Water \\
\hline Adsorption & $1.42(2)$ & $1.92(5)$ & & $0.28(2)$ & $0.24(6)$ \\
Desorption & $1.51(1)$ & $1.48(4)$ & & $0.39(3)$ & $0.20(5)$ \\
\hline
\end{tabular}

same calculations were performed for the pressure dependence of $\mathrm{I}_{4}$ obtained during adsorption and desorption of water (Maheshwari et al. 2017). Comparing them allows to draw some conclusions about differences in adsorption of both liquids. It should be remembered that this approach is a simplification, but it allows to clearly show the relationship between results even at the present preliminary stage of research.

All but one average pore diameters $\left(D_{\text {avg }}\right.$, Table 1$)$ obtained by fitting Gaussian functions to the PSDs are smaller than expected for SBA-3 based on the nitrogen adsorption measurement ( $2 \mathrm{~nm}$, (Maheshwari et al. 2017)) and PALS (1.84(1) nm, according to the ETE model (Goworek et al. 1998)). A similar discrepancy was already observed for thermal desorption of $\mathrm{n}$-hexane from $3 \mathrm{~nm}$ silica pores (Stefaniak et al. 2003). It is hardly explained with the formation of a monolayer, because also the molecules, which are adjacent to the pore walls, should participate in the formation of o-Ps bubbles, and consequently should not be distinguished by PALS. The monolayer formation would result in the opposite effect (i.e. overestimation of pore sizes). o-Ps bubbles cannot form in such layer and the liquid do not contribute to $\mathrm{I}_{4}$. Therefore, the shift of the pore sizes is most likely attributed to the inaccuracy of the Kelvin equation. The model used in this equation assumes liquid as a continuous medium forming meniscus of a hemispherical shape, while it is hardly the case if the size of molecules of the liquid are only several times smaller than the pore size in SBA-3.

The difference in $\mathrm{I}_{4}$ between adsorption and desorption of n-heptane, which was described previously as different slopes, is also visible in PSDs as the $6 \%$ shift of $\mathrm{D}_{\text {avg }}$ and $27 \%$ greater width of the distribution. Because the real pore distribution is always the same, these discrepancies have to reflect differences in the course of adsorption and desorption. Additionally, they may be due to the already mentioned limitations of the $\mathrm{I}_{4}$ applicability, which only detects sufficiently large liquid clusters. In this case it can indicate fragmentation of the liquid at the initial phase of desorption, e.g. due to cavitation inside filled pores. Nevertheless, the observed discrepancies are too small to allow reliable interpretation.

A significantly larger difference in PSD between adsorption and desorption is observed for water. The difference in $\mathrm{D}_{\text {avg }}$ is $23 \%$ and only $17 \%$ in $\sigma_{\mathrm{D}}$, but it should be noticed that the uncertainty is $40 \%$ in this second case. The discrepancy between both $\mathrm{D}_{\text {avg }}$ values found for water can be explained if the formation of the silica-liquid interface (represented by $\mathrm{I}_{3}$ ) is taken into account. Among all sorption dependences for $\mathrm{n}$-heptane and water, water adsorption shows the greatest shift towards larger pressure (ca. $0.1 \mathrm{p}_{0}$ ) of the pressure dependence of $I_{4}$ in relation to $I_{3}$ (Maheshwari et al. 2017). Hence, the silica-water interface is formed at least partially before water filling pores is detected. This suggests that initially water forms numerous liquid clusters, which size is too small to host an o-Ps bubble, at local hydrophilic sites on the pore walls. Strong hydrogen bonds in water make that its molecules prefer to stay together over making bridges to other clusters. The main peak in the PSD appears only when the number and size of the clusters are sufficiently large that they have to merge into water plugs that are capable to host o-Ps bubbles. This interpretation is supported by the tail in the PSD from the side of smaller pore sizes, 
which represents a fraction of larger clusters merged from the accidentally closely formed small ones (Fig. 2).

The above scenario is not repeated during desorption, because, conversely, strong bonding of water prevents splitting it into small clusters. In consequence, water evaporation from the pores proceeds in agreement with the classic capillary condensation model. Therefore, the PSD derived from the water desorption matches these found with n-heptane. The agreement is surprisingly good, which confirms the credibility of this approach.

\section{Conclusions}

Monitoring of adsorption by PALS bases on a different principle of detecting the amount of condensed adsorbate than in the case of the volumetric porosimetry. A unique advantage of PALS is the ability to detect the size and concentration of those parts of pores that are free of an adsorbate. Simultaneously, the amount of adsorbate can be monitored. However, PALS detects directly only the part of the adsorbate that forms clusters of a size exceeding a certain threshold (apparently several $\mathrm{nm}^{3}$ ). In addition, the PALS results provide the information about changes in the surface area of the interface between the adsorbate and adsorbent. This makes PALS a promising method to improve the insight into the course of sorption.

Some interesting conclusions about the course of adsorption can be found on the basis of discrepancies in PALS results for adsorption and desorption. In particular, the possibility of a separate detection of the liquid-solid interface and clustered liquid improves the insight into the course of sorption. This allows to discuss the evolution of the form and location of $\mathrm{n}$-heptane condensates during adsorption and desorption. It seems that layer by layer adsorption of n-heptane does not occur in the pores of SBA-3. This statement is supported by the fact that their diameter is only about twice the length of the n-heptane molecule. Full coverage of silica by $n$-heptane is detected only when the pores are filled in over $2 / 3$. This suggests existence of empty bubbles in n-heptane in the last stage of adsorption. At the beginning of desorption similar bubbles seem to appear at even higher pressure.

Even more detailed information can be obtained by comparing sorption of various adsorbates on the same adsorbent. The choice of water and n-heptane gives the opportunity to observe and interpret significant differences between the sorption of polar and non-polar adsorbate on the polar surface of silica. The comparison is easier if the PALS results are transformed into pore size distributions. Because all PSDs concern the same material, they should be identical. However, because this is not the case, the differences should reflect different course of adsorption and desorption.
Additionally, these differences should be discussed in relation to the specifics of the PALS method.

An approach, which consists in comparing PSDs, allows to presume that water adsorption begins with the appearance of many sub-nanometre sized droplets at the polar centres present on the silica walls. The droplets mostly do not join each other until their density (or size) is high enough for their mutual overlap. This is justified by strong mutual interaction between water molecules. This scenario is not followed during desorption, which occurs in the way much more similar way to that of n-heptane, as evidenced by the similarity between PSDs derived from desorption of water and n-heptane.

Definitely a drawback of PSDs obtained from PALS is the lack of the absolute values of the volume. Although a calibration of the intensity related to the liquid can be done, its results would be hardly applicable to every class of materials.

Although the migration of ortho-positronium is not the main subject of this work, some conclusions on this topic may be important for future PALS studies. The most important observation is that the change in the probability of o-Ps migration affects not only changes in the intensity of the o-Ps component ascribed to intergranular spaces. Simultaneously, its lifetime is also greatly changed. However, this effect is not directly related to the migration effect, but to the cause of its change, i.e. filling the openings of primary pores with a liquid that changes the average electron density on the surface of intergranular spaces.

Open Access This article is distributed under the terms of the Creative Commons Attribution 4.0 International License (http://creativeco mmons.org/licenses/by/4.0/), which permits unrestricted use, distribution, and reproduction in any medium, provided you give appropriate credit to the original author(s) and the source, provide a link to the Creative Commons license, and indicate if changes were made.

\section{References}

Agah, S., Pasquali, M., Kolomeisky, A.B.: Theoretical analysis of selectivity mechanisms in molecular transport through channels and nanopores. J. Chem. Phys. 142(4), 044705 (2015). https://doi. org/10.1063/1.4906234

Babarao, R., Jiang, J.: Molecular computations of adsorption in nanoporous materials. In: Dunne, L.J., Manos, G. (eds.) Adsorption and Phase Behaviour in Nanochannels and Nanotubes, pp. 69-100. Springer, Dordrecht (2010). https://doi. org/10.1007/978-90-481-2481-7_4

Brunauer, S., Emmett, P.H., Teller, E.: Adsorption of gases in multimolecular layers. J. Am. Chem. Soc. 60(2), 309-319 (1938). https ://doi.org/10.1021/ja01269a023

Całus, S., Kityk, A.V., Eich, M., Huber, P.: Inhomogeneous relaxation dynamics and phase behaviour of a liquid crystal confined in a nanoporous solid. Soft Matter 11(16), 3176-3187 (2015). https ://doi.org/10.1039/C5SM00108K 
Chen, F., Xu, X.-J., Shen, S., Kawi, S., Hidajat, K.: Microporosity of SBA-3 mesoporous molecular sieves. Microporous Mesoporous Mater. 75(3), 231-235 (2004). https://doi.org/10.1016/j.micro meso.2004.07.028

Crupi, V., Majolino, D., Migliardo, P., Venuti, V.: Neutron scattering study and dynamic properties of hydrogen-bonded liquids in mesoscopic confinement. 1. The water case. J. Phys. Chem. B 106(42), 10884-10894 (2002). https://doi.org/10.1021/jp020503m

Dabelstein, W., Reglitzky, A., Schütze, A., Reders, K.: Automotive Fuels. In: Ullmann's Encyclopedia of Industrial Chemistry. WileyVCH Verlag GmbH \& Co. KGaA, Weinheim (2000)

Docampo-Álvarez, B., Gómez-González, V., Montes-Campos, H., Otero-Mato, J.M., Méndez-Morales, T., Cabeza, O., Gallego, L.J., Lynden-Bell, R.M., Ivaništšev, V.B., Fedorov, M.V., Varela, L.M.: Molecular dynamics simulation of the behaviour of water in nano-confined ionic liquid-water mixtures. J. Phys.: Condens. Matter 28(46), 464001 (2016). https://doi.org/10.1088/0953$8984 / 28 / 46 / 464001$

Ferrell, R.A.: Long lifetime of positronium in liquid helium. Phys. Rev. 108(2), 167-168 (1957). https://doi.org/10.1103/PhysRev.108.167

Goworek, T., Ciesielski, K., Jasinska, B., Wawryszczuk, J.: Positronium states in the pores of silica gel. Chem. Phys. 230(2-3), 305-315 (1998). https://doi.org/10.1016/S0301-0104(98)00068-8

Hautojärvi, P.: Positrons in Solids. Topics in Current Physics, vol. 12. Springer, Berlin (1979)

Ito, K., Yoshimoto, S., O'Rourke, B.E., Oshima, N., Kumagai, K.: Subnanopore filling during water vapor adsorption on microporous silica thin films as seen by low-energy positron annihilation. Appl. Phys. Lett. 112(8), 083701 (2018). https://doi. org/10.1063/1.5021105

Jiang, W., Wang, Y., Voth, G.A.: Molecular dynamics simulation of nanostructural organization in ionic liquid/water mixtures. J. Phys. Chem. B 111(18), 4812-4818 (2007). https://doi.org/10.1021/ jp0671421

Kansy, J.: Microcomputer program for analysis of positron annihilation lifetime spectra. Nucl. Instrum. Methods Phys. Res., Sect. A 374(2), 235-244 (1996). https://doi.org/10.1016/01689002(96)00075-7

Kierys, A., Zaleski, R., Gorgol, M., Goworek, J.: N-Heptane adsorption in periodic mesoporous silica by in situ positron annihilation lifetime spectroscopy. Microporous Mesoporous Mater. 179, 104-110 (2013a). https://doi.org/10.1016/j.micromeso.2013.05.022

Kierys, A., Zaleski, R., Tydda, M., Goworek, J.: What can positronium tell us about adsorption? Adsorption 19(2-4), 529-535 (2013b). https://doi.org/10.1007/s10450-013-9475-x

Kolomeisky, A.B., Kotsev, S.: Effect of interactions on molecular fluxes and fluctuations in the transport across membrane channels. J. Chem. Phys. 128(8), 085101 (2008). https://doi. org/10.1063/1.2831801

Lin, D., Ding, Z., Liu, L., Ma, R.: Experimental study of vapor permeation of C5C7 alkane through PDMS membrane. Chem. Eng. Res. Des. 90(11), 2023-2033 (2012). https://doi.org/10.1016/j. cherd.2012.03.007

Liu, Y., Feng, X., Lawless, D.: Separation of gasoline vapor from nitrogen by hollow fiber composite membranes for VOC emission control. J. Membr. Sci. 271(1-2), 114-124 (2006). https://doi. org/10.1016/j.memsci.2005.07.012

Maheshwari, P., Gorgol, M., Kierys, A., Zaleski, R.: Positron probing of liquid-free volume to investigate adsorption-desorption behavior of water in two-dimensional mesoporous SBA-3. J. Phys. Chem. C 121(32), 17251-17262 (2017). https://doi.org/10.1021/ acs.jpcc.7b04317

Saihara, K., Yoshimura, Y., Ohta, S., Shimizu, A.: Properties of water confined in ionic liquids. Sci. Rep. 5, 10619 (2015). https://doi. org/10.1038/srep10619

Sparreboom, W., van den Berg, A., Eijkel, J.C.: Principles and applications of nanofluidic transport. Nat. Nanotechnol. 4(11), 713-720 (2009). https://doi.org/10.1038/nnano.2009.332

Stefaniak, W., Goworek, J., Bilinski, B.: Pore size analysis by nitrogen adsorption and thermal desorption. Colloids Surf. A: Physicochem. Eng. Aspects 214(1-3), 231-237 (2003). https://doi. org/10.1016/S0927-7757(02)00413-2

Thomson, W.: LX. On the equilibrium of vapour at a curved surface of liquid. Lond. Edinb. Dublin Philos. Mag. J. Sci. 42(282), 448-452 (1871). https://doi.org/10.1080/14786447108640606

Wheeler, T.D., Stroock, A.D.: The transpiration of water at negative pressures in a synthetic tree. Nature 455(7210), 208-212 (2008). https://doi.org/10.1038/nature07226

Zaleski, R.: Principles of positron porosimetry. Nukleonika 60(4), 795-800 (2015). https://doi.org/10.1515/nuka-2015-0143

Zaleski, R., Błażewicz, A., Kierys, A.: Ortho-positronium migration in mesopores of MCM-41, MSF and SBA-3. Nukleonika 58(1), 233-238 (2013)

Zaleski, R., Dolecki, W., Kierys, A., Goworek, J.: n-Heptane adsorption and desorption on porous silica observed by positron annihilation lifetime spectroscopy. Microporous Mesoporous Mater. 154, 142147 (2012). https://doi.org/10.1016/j.micromeso.2011.08.032

Zaleski, R., Kierys, A., Gorgol, M.: Positron insight into evolution of pore volume and penetration of the polymer network by n-heptane molecules in mesoporous XAD4. Phys. Chem. Chem. Phys. 19(15), 10009-10019 (2017). https://doi.org/10.1039/C7CP0 $0101 \mathrm{~K}$

Zandavi, S.H., Ward, C.A.: Contact angles and surface properties of nanoporous materials. J. Colloid Interface Sci. 407, 255-264 (2013). https://doi.org/10.1016/j.jcis.2013.06.062

Zhang, L., Peng, Y., Zhang, J., Chen, L., Meng, X., Xiao, F.-S.: Adsorptive and catalytic properties in the removal of volatile organic compounds over zeolite-based materials. Chin. J. Catal. 37(6), 800-809 (2016). https://doi.org/10.1016/S1872-2067(15)61073-7

Zhang, X., Gao, B., Creamer, A.E., Cao, C., Li, Y.: Adsorption of VOCs onto engineered carbon materials: a review. J. Hazard. Mater. 338, 102-123 (2017). https://doi.org/10.1016/j.jhazm at.2017.05.013

Publisher's Note Springer Nature remains neutral with regard to jurisdictional claims in published maps and institutional affiliations. 